\title{
QUALITY OF LIFE OF PATIENTS WITH PSORIASIS
}

\author{
Jindra Šmejkalová1, Lenka Borskáa , Květa Hamákováa ${ }^{3}$ Lenka Hodačová4, Eva Čermáková5, Zdeněk Fiala ${ }^{1}$ \\ 'Department of Hygiene and Preventive Medicine, Faculty of Medicine in Hradec Králové, Charles University, Hradec Králové, Czech Republic \\ 2Department of Pathological Physiology, Faculty of Medicine in Hradec Králové, Charles University, Hradec Králové, Czech Republic \\ ${ }^{3}$ Department of Dermatology and Venerology, Faculty Hospital Hradec Králové, Hradec Králové, Czech Republic \\ ${ }^{4}$ Department of Social Medicine, Faculty of Medicine in Hradec Králové, Charles University, Hradec Králové, Czech Republic \\ ${ }^{5}$ Computer Technology Centre, Faculty of Medicine in Hradec Králové, Charles University, Hradec Králové, Czech Republic
}

\section{SUMMARY}

Objective: The two main aims of our study were to assess the quality of life (QOL) of patients with moderate or severe psoriasis treated by Goeckerman therapy and to compare QOL of our patients on the date of admission and 1 month after their discharge.

Methods: We performed a prospective study on 51 patients treated for chronic plaque psoriasis by Goeckerman regimen (GR). The psoriasis area involvement and severity was measured using the Psoriasis Area and Severity Index (PASI). Patients' health-related QOL was evaluated using Psoriasis Disability Index (PDI).

Results: In our study we demonstrated that the QOL of this sample of 51 patients with severe forms of psoriasis was relatively good; an average PDI value on the day of admission was 9.02 , which represents a small effect on patient's QOL. We did not find any significant differences in QOL between younger and older respondents or between men and women. Despite good treatment efficiency, we did not find improvement in QOL 1 month after discharge.

Conclusions: The QOL of our patients was relatively good. This could be explained by the fact that our patients have been suffering from psoriasis for many years and have probably adapted to their disease. QOL of our patients was not directly dependent on the extent and intensity of skin changes. Further studies on the connection between psoriasis therapy and patients' QOL are still highly needed.

Key words: psoriasis, quality of life, Goeckerman therapy

Address for correspondence: J. Šmejkalová, Charles University, Faculty of Medicine in Hradec Králové, Šimkova 870, 50003 Hradec Králové, Czech Republic. E-mail: smejkal@lfhk.cuni.cz

https://doi.org/10.21101/cejph.a5611

\section{INTRODUCTION}

Psoriasis is a chronic dermatologic disease severely affecting the lives of patients as a result of daily life restrictions based on feelings of shame and dissatisfaction. Generally, we can say that the majority of skin diseases greatly reduce patients' quality of life (QOL), especially if the disease affects visible parts of the body and is associated with systemic complications or unpleasant subjective symptoms. The same applies to psoriasis and many studies have mentioned an inverse relationship between QOL and severity of the disease $(1,2)$. Most of the published assessments of psoriasis treatment have used doctor-based measures of disease extent and severity, such as the Psoriasis Area and Severity Index (PASI) scoring system, which do not comprise the patients' point of view (3).

The use of standardised questionnaires evaluating QOL allows comparison of patients' quality of life prior to treatment and following recovery. Moreover, understanding the feelings of a patient is crucial for obtaining confidence, ensuring compliance and therapeutic success.

The most frequent subjective complaints of psoriatic patients were difficulties in the workplace, job acquisition, problematic social relationships, exclusion from public facilities, and suicidal ideation. Younger patients reported difficulties in sexual activities more frequently in contrast to the older respondents, who reported exacerbated difficulties in daily activities such as using their hands or walking. The authors have assumed that certain limitations in QOL are attributed more to patients' comorbidities than to psoriasis as such (4). It has been proved that psoriasis is associated with higher risk of cardiovascular disease, diabetes and overweight or obesity (5). Obese people are more likely to have severe psoriasis and psoriatic arthritis than people with an average body mass index. Psoriatic arthritis was diagnosed in $31 \%$ of respondents (6). Due to the nature of their illness patients experience stigmatisation (7) and are prone to suffer from depression and/or anxiety (8). The actual disability was stated to be comparable to other major illnesses such as cancer, hypertension or diabetes (9).

There are many questionnaire methods that assess the quality of life of patients suffering from psoriasis (10). In our study we used the Psoriasis Disability Index (PDI).

There were two main aims of this study: to assess the quality of life of patients with moderate or severe psoriasis treated by Goeckerman therapy (GT), and to compare QOL of our patients on the date of admission and 1 month after their discharge from hospital. 


\section{MATERIALS AND METHODS}

\section{Study Design}

We performed a prospective study on a convenient sample of 51 patients treated at the Department of Dermatology and Venerology, Faculty Hospital Hradec Králové, for chronic plaque psoriasis by Goeckerman regimen (GR). This therapeutic method represents a daily local treatment of psoriasis by topical dermal application of crude coal tar (5\%), containing polycyclic aromatic hydrocarbons, and dermal exposure to UV-A and UV-B radiation. The original Goeckerman therapy was formulated in 1925 for the treatment of psoriasis. It has since been used in modern dermatology as an extremely effective treatment in terms of speed of improvement, probability of achieving a PASI score improvement of at least $75 \%$ within 3 months or sooner, and duration of remission. The cost-effectiveness of this therapy in comparison with the cost of new biological agents should be mentioned as well (11-13).

Informed consent of each subject was obtained. All participants were asked to complete the questionnaire according to their own feelings and opinions. Those who had difficulties with completing the questionnaire were assisted by a trained counsellor. The study was approved by the Ethics Committee of the Medical Faculty of Charles University, University Hospital and Purkyně Military Medical Academy in Hradec Králové.

\section{Clinical Assessment}

All clinical evaluations were performed by one dermatologist throughout the whole study. The psoriasis area involvement and severity were measured using the Psoriasis Area and Severity Index. The PASI is the most widely used measure of severity in research and clinical settings. Four main areas were assessed for calculation of the PASI scores: head, trunk, upper extremities, and lower extremities, corresponding to $10 \%, 20 \%, 30 \%$, and $40 \%$ of the total body area, respectively. The maximum score for PASI is 72 .

\section{Quality of Life Assessment}

The patients' health-related QOL was evaluated using the Psoriasis Disability Index. The PDI, developed by Finlay and Coles, concerns the functional lifestyle disabilities caused by psoriasis (14). It contains a 15 -item scale that specifically addresses self-reported disability in areas of daily activities, employment, personal relationships, leisure, and effects of the treatment. The PDI is calculated using the score of each of 15 questions resulting in a maximum of 45 and minimum of 0 . The scoring of each question was based on a series of 4 responses: not at all (score 0 ), a little (score 1), quite a lot (score 2 ), very much (score 3 ). If a question is left unanswered the score taken is 0 . When two or more items of the PDI were not responded to, the questionnaire was excluded from the analysis. The higher the score, the worse QOL. Scores in the range of 1-15 reflect minor impairment, 16-30 significant and 31-45 severe QOL impairment.

\section{Statistical Analysis}

All data were analyzed statistically with NCSS 11 (NCSS 11 Statistical Software (2016). NCSS, LLC. Kaysville, Utah,
USA. The results are presented by mean (standard deviation). Changes in time were evaluated by paired t-test or the nonparametric Wilcoxon signed rank test. Either the two-sample t-test or the nonparametric Mann-Whitney test were used to evaluate the differences between groups. The strength of the relationship was expressed by Spearman's correlation. A level of significance $\alpha=0.05$ was selected.

\section{RESULTS}

The PDI questionnaire survey carried out from 2016-2017 was non-randomized and conducted on a convenient sample of psoriatic patients. The survey was attended only by those patients who agreed to be included in the study and gave informed consent. Clinical assessment by PASI and quality of life by PDI was carried out two times for each patient - at the time of their admission and 1 month following discharge from hospital.

Table 1. Characteristics of respondents $(N=51)$

\begin{tabular}{|l|c|c|}
\hline Mean age (years) & \multicolumn{2}{|c|}{$49.3 \pm 16.1$} \\
\hline Number of years with psoriasis & \multicolumn{2}{|c|}{$12.6 \pm 9.4$} \\
\hline Younger ( $\leq 50)$ 22 respondents & \multicolumn{2}{|c|}{$18.6 \pm 17.7$} \\
\hline Older (> 50) 29 respondents & $\mathrm{n}$ & $\%$ \\
\hline & 21 & 41 \\
\hline Males & 30 & 59 \\
\hline Females & &
\end{tabular}

\begin{tabular}{|l|c|c|}
\hline Marital status \\
\hline Single & 15 & 29 \\
\hline Married & 29 & 57 \\
\hline Partner & 1 & 2 \\
\hline Divorced & 6 & 12 \\
\hline
\end{tabular}

\begin{tabular}{|l|c|c|}
\hline \multicolumn{2}{|l|}{ Education level } \\
\hline Elementary & 10 & 19 \\
\hline Trained & 35 & 69 \\
\hline High school & 4 & 8 \\
\hline University & 2 & 4 \\
\hline
\end{tabular}

\begin{tabular}{|l|c|c|}
\hline \multicolumn{3}{|l|}{ Smoking } \\
\hline Current smoker & 26 & 51 \\
\hline Former smoker & 1 & 1 \\
\hline Non-smoker & 24 & 47 \\
\hline
\end{tabular}

\begin{tabular}{|c|c|c|}
\hline \multicolumn{3}{|l|}{ Health state } \\
\hline Diabetes & 7 & 14 \\
\hline Psoriatic arthritis & 11 & 22 \\
\hline $\begin{array}{l}\text { Mental problems (anxiety, depres- } \\
\text { sion, paranoia) }\end{array}$ & 3 & 6 \\
\hline $\begin{array}{l}\text { Cardiovascular diseases including } \\
\text { hypertension }\end{array}$ & 18 & 35 \\
\hline Oncological disease & 0 & 0 \\
\hline Overweight (BMI 25.0-29.9) & 17 & 33 \\
\hline Obesity $(\geq 30)$ & 17 & 33 \\
\hline Other health disorders & 14 & 27 \\
\hline
\end{tabular}


The general characteristics of the respondents are illustrated in Table 1 . The study comprised 51 adult patients (21 men and 30 women) of mean age 49.3 (range 18-76) years. More than 50\% of our respondents were married (57\%), approximately one third were single. Most of the patients had an elementary level of education or were trained. The set was composed of $51 \%$ smokers, 1 former smoker and $47 \%$ were non-smokers. Sixty-six percent of respondents had higher weight, 33.3\% suffered from overweight and the same number from obesity.

To assess the comorbidity of psoriatic patients, we inquired about their health status - especially cardiovascular diseases, obesity, psoriatic arthritis, and any psychological problems. The results we obtained are certainly influenced by the subjective responses of our patients as their health status was not objectively assessed by medical examination. Most often, our patients reported cardiovascular disease including hypertension (35\%), which could be related to the higher age of the respondents. One fifth of the respondents reported difficulty with psoriatic arthritis (22\%) and $14 \%$ suffered from diabetes. Only $6 \%$ of the respondents mentioned psychological problems, which may indicate a possible dissimulation or underestimation of problems.

In Table 2 we present changes in PASI and total PDI, as well as in individual domains of PDI, at the time of admission and 1 month after the treatment. The table shows significant improvement in health status after receiving Goeckerman therapy (decrease of PASI from 18.29 to 5.99).

A somewhat unexpected finding was that the QOL of our respondents was relatively good. The mean score of PDI prior to admission was 9.02, meaning minor impairment. A slight surprise for us was the comparison of QOL before and after treatment. In accordance with a large quantity of literature data we expected some improvement in QOL, particularly with regard to a significant improvement in the PASI score. Despite the efficiency of GR, the improvement of health condition was not associated with improved QOL. Our results showed that one month after discharge there was an insignificant deterioration in some quality of life domains (employment, personal relationship, leisure), although in other domains (daily activities, treatment) the deterioration was statistically significant. We did not find any correlation between the extent of skin damage (PASI) and the quality of life (PDI) by correlation analysis. Spearman's correlation coefficient was -0.031 on the day of admission and -0.097 one month after discharge from hospital.
Table 3 shows that despite the relatively poor clinical status (PASI 18.29) almost 3/4 respondents reported that their daily activities are not negatively affected by the disease. The only exception was in the data indicating the need for frequent change of clothing.

A greater impact of psoriasis was reported in terms of work activities. Only $32 \%$ of respondents think that their illness does not increase time off work, $52 \%$ think that psoriasis does not prevent them from doing their job and $78 \%$ of respondents believe that psoriasis does not affect their career (question 8).

We did not find any significant complaints either in sexual matters or social relations. Mild sexual difficulties and/or problems with social relations caused by psoriasis were mentioned by only $18 \%$ of respondents and only one person has identified these problems as large or very large.

The answers to the questions mapping leisure time were more negative. Mild difficulties in social and sport activities were reported by $21 \%$ and $23 \%$ of respondents, respectively, whereas $20 \%$ and $12 \%$ of respondents reported these problems as very large. Problems with using communal bathing were the most frequent.

Most respondents (88\%) thought that their potential negative habits, such as smoking or alcohol consumption, were not affected by psoriasis. Similarly, our respondents did not see the association between their disease and degree of tidiness in their homes. Only $12 \%$ consider this relationship to be significant.

Table 4 presents the answers to individual questions from the PDI questionnaire one month after discharge. Despite the significant improvement in the PASI, we found minor, mostly insignificant, deterioration in QOL (total PDI 10.2) one month after discharge. The percentage of respondents who believe that psoriasis does not affect their QOL declined particularly in the daily activities and the treatment domains $(p<0.011, p<0.024$, respectively) (Table 2).

Tables 5 and 6 present the influence of age and sex on PDI and PASI domains before and after treatment with the modified Goeckerman regimen. We did not find any significant differences in QOL between younger and older respondents, although in accordance with some literature data the QOL of older respondents was slightly worse (although non-significantly), mainly 1 month after discharge from the hospital (9.18 vs. 11.3). The biggest difference in PDI of younger and older respondents was found in the domain of daily activities. Regarding the difference in QOL

Table 2. Changes in domains of PDI and PASI before and after receiving modified Goeckerman regimen $(N=51)$

\begin{tabular}{|l|c|c|c|}
\hline \multirow{2}{*}{} & Before admission & 1 month after discharge & \multirow{2}{*}{ p-value } \\
\cline { 2 - 4 } & Mean (SD) & Mean (SD) & $<0.001$ \\
\hline PASI & $18.3(7.34)$ & $5.99(2.79)$ & 0.089 n.s. \\
\hline Dotal PDI & $9.02(7.16)$ & $10.2(7.38)$ & 0.011 \\
\hline Employment & $3.35(2.75)$ & $4.27(2.97)$ & 0.661 n.s. \\
\hline Personal relationship & $2.37(2.44)$ & $2.33(2.46)$ & 0.105 n.s. \\
\hline Leisure & $0.49(0.86)$ & $0.59(0.96)$ & 0.635 n.s. \\
\hline Treatment & $2.39(2.48)$ & $2.45(2.40)$ & 0.024 \\
\hline PASI vs. total PDI $(r)$ & $0.41(0.75)$ & $0.59(0.87)$ & -0.097 \\
\hline
\end{tabular}

$\mathrm{r}$ - Spearman correlation coefficient; PASI - Psoriasis Area and Severity Index; PDI - Psoriasis Disability Index 
Table 3. Domains and questions of PDI at time of admission and hospitalisation

\begin{tabular}{|c|c|c|c|c|}
\hline & Not at all (\%) & A little (\%) & $A \operatorname{lot}(\%)$ & Very much (\%) \\
\hline \multicolumn{5}{|l|}{ Daily activities } \\
\hline PDI 1: Problems with house work & 61 & 21 & 16 & 2 \\
\hline PDI 2: Wore different type of clothes & 72 & 12 & 16 & 0 \\
\hline PDI 3: More frequent change of clothes & 23 & 26 & 43 & 8 \\
\hline PDI 4: Problems at hair dressers & 82 & 12 & 2 & 4 \\
\hline PDI 5: More frequent baths & 61 & 14 & 20 & 6 \\
\hline \multicolumn{5}{|l|}{ Employment related } \\
\hline PDI 6a: More time off work & 32 & 24 & 28 & 16 \\
\hline $\begin{array}{l}\text { PDI 6b: If not at work or school: to what extent has psoriasis } \\
\text { interfered with normal daily activities? }\end{array}$ & 38 & 35 & 23 & 4 \\
\hline PDI 7a: Prevented from doing work & 52 & 16 & 24 & 8 \\
\hline $\begin{array}{l}\text { PDI } 7 b \text { : If not at work or school: to what extent has psoriasis } \\
\text { altered the way in which you carry out normal daily activities? }\end{array}$ & 46 & 27 & 19 & 8 \\
\hline PDI 8: Career affected & 78 & 10 & 6 & 6 \\
\hline \multicolumn{5}{|l|}{ Personal relationships } \\
\hline PDI 9: Sexual difficulties & 80 & 18 & 2 & 0 \\
\hline PDI 10: Problems with social relations & 78 & 18 & 2 & 2 \\
\hline \multicolumn{5}{|l|}{ Leisure } \\
\hline PDI 11: Social activity affected & 59 & 21 & 14 & 6 \\
\hline PDI 12: Sports activity affected & 65 & 23 & 12 & 0 \\
\hline PDI 13: Problems with using communal bathing & 53 & 14 & 8 & 25 \\
\hline PDI 14: More smoking/drinking & 88 & 8 & 4 & 0 \\
\hline \multicolumn{5}{|l|}{ Treatment } \\
\hline $\begin{array}{l}\text { PDI 15: To what extent has your psoriasis or treatment made } \\
\text { your home messy or untidy? }\end{array}$ & 72 & 16 & 10 & 2 \\
\hline
\end{tabular}

PDI - Psoriasis Disability Index. Every question relates to the last four weeks.

between men and women, we found no statistically significant differences (Table 6).

\section{DISCUSSION}

In our study, we demonstrated that the QOL of a convenient sample of 51 patients with severe forms of psoriasis was relatively good. Our patients had an average PDI value of 9.02 out of 45 , signifying a small or moderate effect on patient's QOL. These results imply that our findings do not coincide with the general assumption that the QOL of psoriatic patients negatively correlates with the severity of the skin disability $(1,2)$. In our research, we did not find correlation between the extent of skin damage (PASI) and quality of life (PDI). Spearman's correlation coefficient (r) was -0.031 on the day of admission and -0.097 one month after hospital discharge. Nevertheless, similar results are not unique in the literature. Some other authors have reported similar findings of a relatively good QOL of psoriatic patients (15-18).

It should be emphasized that for analysis of the results of these studies, the severity of skin involvement, age and gender of the patients should be considered. Age and duration of psoriasis are significant predictors of health-related QOL (19). Patients who had longer disease duration reported less impairment of QOL. It seems that individuals who suffered from the disease for more than 10 years may be less emotionally affected by interpersonal difficulties; they may also have learned to cope better with certain aspects of living with psoriasis. The same interpretation was used in publications by Czech authors $(20,21)$ who reported relatively good QOL for psoriatic patients, particularly in terms of personal relationships, daily activities or treatment. These findings are explained by the fact that the observed patients have been suffering from psoriasis for many years and have eventually learned to live and/or cope with their disease. Coping strategies used most frequently by psoriatic patients are acceptance, planning, active coping, positive reinterpretation, and humor (22). It is not only the number of years lived with the disease but also age and gender that play a role, as younger patients and females had a statistically significant decrease in QOL (23). Another problem is that the reported declining influence of psoriasis on daily activities in elderly patients may be attributed more to the increasing influence of some comorbidities (especially arthrosis) on these activities $(9,24)$.

In our set of patients we also found a higher incidence of various comorbidities. The most frequent was the occurrence of cardiovascular diseases (35\%) and psoriatic arthritis (22\%), which could be related to the higher age of the respondents. A questionnaire inquiry revealed the occurrence of some risk factors 
Table 4. Domains and questions of PDI one month after discharge

\begin{tabular}{|c|c|c|c|c|}
\hline & Not at all (\%) & A little (\%) & A lot $(\%)$ & Very much (\%) \\
\hline \multicolumn{5}{|l|}{ Daily activities } \\
\hline PDI 1: Problems with house work & $\downarrow 43$ & $\uparrow 41$ & 14 & 2 \\
\hline PDI 2: Wore different type of clothes & $\downarrow 45$ & $\uparrow 25$ & $\uparrow 27$ & 2 \\
\hline PDI 3: More frequent change of clothes & 20 & $\uparrow 35$ & $\downarrow 39$ & 6 \\
\hline PDI 4: Problems at hair dressers & $\downarrow 74$ & $\uparrow 18$ & 4 & 4 \\
\hline PDI 5: More frequent baths & $\downarrow 43$ & $\uparrow 22$ & $\uparrow 29$ & 6 \\
\hline \multicolumn{5}{|l|}{ Employment related } \\
\hline PDI 6a: More time off work & $\uparrow 46$ & $\downarrow 21$ & $\downarrow 21$ & $\downarrow 12$ \\
\hline $\begin{array}{l}\text { PDI 6b: If not at work or school: to what extent has psoriasis } \\
\text { interfered with your normal daily activities? }\end{array}$ & $\uparrow 44$ & $\downarrow 30$ & 22 & 4 \\
\hline PDI 7a: Prevented from doing work & 54 & $\uparrow 21$ & 17 & 8 \\
\hline $\begin{array}{l}\text { PDI } 7 b \text { : If not at work or school: to what extent has psoriasis } \\
\text { altered the way in which you carry out normal daily activities? }\end{array}$ & 44 & 26 & $\uparrow 26$ & 4 \\
\hline PDI 8: Career affected & $\downarrow 70$ & 12 & 8 & $\uparrow 10$ \\
\hline \multicolumn{5}{|l|}{ Personal relationships } \\
\hline PDI 9: Sexual difficulties & 80 & 14 & 6 & 0 \\
\hline PDI 10: Problems with social relations & 76 & 16 & 6 & 2 \\
\hline \multicolumn{5}{|l|}{ Leisure } \\
\hline PDI 11: Social activity affected & $\downarrow 43$ & $\uparrow 35$ & $\uparrow 20$ & 2 \\
\hline PDI 12: Sports activity affected & $\downarrow 59$ & 23 & $\uparrow 16$ & 2 \\
\hline PDI 13: Problems with using communal bathing & 55 & $\uparrow 20$ & $\uparrow 14$ & $\downarrow 12$ \\
\hline PDI 14: More smoking/drinking & 88 & 6 & 2 & 2 \\
\hline \multicolumn{5}{|l|}{ Treatment } \\
\hline $\begin{array}{l}\text { PDI 15: To what extent has your psoriasis or treatment made } \\
\text { your home messy or untidy? }\end{array}$ & $\downarrow 61$ & $\uparrow 25$ & 8 & $\uparrow 6$ \\
\hline
\end{tabular}

PDI - Psoriasis Disability Index. Every question relates to the last four weeks.

Table 5. Influence of age on domains of PDI and PASI before and after receiving modified Goeckerman regimen

\begin{tabular}{|c|c|c|c|c|}
\hline & \multicolumn{2}{|c|}{ Before admission } & \multicolumn{2}{|c|}{1 month after discharge } \\
\hline & \multicolumn{2}{|c|}{ Mean (SD) } & \multicolumn{2}{|c|}{ Mean (SD) } \\
\hline & $\leq 50(n=22)$ & $>50(n=29)$ & $\leq 50(n=22)$ & $>50(n=29)$ \\
\hline PASI & $18.9(6.88)$ & $17.8(7.74)$ & $6.12(2.04)$ & $5.89(3.29)$ \\
\hline Total PDI & $8.36(7.48)$ & $9.52(7.01)$ & $9.18(7.27)$ & $11.0(7.37)$ \\
\hline Daily activities & $2.59(2.61)$ & $3.93(2.75)$ & $3.45(3.16)$ & $4.9(2.70)$ \\
\hline Employment & $2.27(2.69)$ & $2.45(2.28)$ & $2.5(2.91)$ & $2.21(2.11)$ \\
\hline Personal relationship & $0.54(1.01)$ & $0.45(0.74)$ & $0.5(0.91)$ & $0.65(1.01)$ \\
\hline Leisure & $2.5(2.63)$ & $2.31(2.41)$ & $2.23(2.45)$ & $2.62(2.39)$ \\
\hline Treatment & $0.45(2.41)$ & $0.38(0.73)$ & $0.5(0.80)$ & $0.65(0.94)$ \\
\hline
\end{tabular}

PASI - Psoriasis Area and Severity Index; PDI - Psoriasis Disability Index.

for cardiovascular disease, such as a high prevalence of smoking and obesity, as well as the risk waist circumference. These are the risk factors which are often mentioned in relation to psoriasis (25). They may, of course, be related to the way of life of people with psoriasis, who are partly handicapped, for example, by some restrictions in the conduct of sports activities. At this point, it should be stressed that the data collected on the health status of the respondents are affected by errors arising from the subjective statements of the patients. This can, for instance, explain the low prevalence of psychological problems reported by our respondents. Nevertheless, there may be a connection to the fact that our patients had relatively good QOL, which may be the reason why they did not complain about their psychological problems as often as the respondents in other studies.

The second objective of our study was to assess the impact of psoriasis treatment on the patients' quality of life. In accordance 
Table 6. Influence of sex on domains of PDI and PASI before and after receiving modified Goeckerman regimen

\begin{tabular}{|l|c|c|c|c|}
\hline \multirow{2}{*}{} & \multicolumn{2}{|c|}{ Before admission } & \multicolumn{2}{c|}{ 1 month after discharge } \\
\cline { 2 - 5 } & \multicolumn{2}{|c|}{ Mean (SD) } & Mean (SD) \\
\cline { 2 - 5 } & Men $(\mathrm{n}=21)$ & $17.7(7.19)$ & $6.81(3.44)$ & Women $(\mathrm{n}=30)$ \\
\hline PASI & $19.2(7.63)$ & $8.4(7.55)$ & $10.1(6.34)$ & $5.42(2.12)$ \\
\hline Total PDI & $9.9(6.65)$ & $3.33(2.99)$ & $3.43(2.69)$ & $10.4(8.04)$ \\
\hline Emily activities & $3.38(2.44)$ & $2.37(2.72)$ & $2.09(1.84)$ & $4.87(3.05)$ \\
\hline Personal relationship & $2.38(2.04)$ & $0.4(0.81)$ & $0.86(1.19)$ & $2.5(2.84)$ \\
\hline Leisure & $0.62(0.92)$ & $2(3.32)$ & $2.95(2.35)$ & $0.4(0.73)$ \\
\hline Treatment & $2.95(2.65)$ & $0.3(0.75)$ & $0.71(0.84)$ & $2.1(2.41)$ \\
\hline
\end{tabular}

with available literature data we expected some improvement in the patients' QOL, particularly with regard to a significant improvement in the PASI score. On the contrary, we have found an insignificant deterioration in some QOL domains (employment, personal relationship, leisure) but also a statistically significant deterioration in daily activities and treatment. The explanation for some deterioration of QOL one month after discharge may be the fact that the patients have to take care of themselves, which might be a bit more demanding in comparison to a hospital regimen. However, this deterioration in QOL (total PDI 10.2) one month after the discharge was minor and mostly insignificant. Significant changes were related only to the domains of daily activities and treatment.

A certain limit of the study may be the relatively low number of respondents. Compared to the number of studies presented both in the prestigious Czech and foreign journals, however, it is a comparable set of patients. The study was non-randomized and the obtained results may not be representative of the general population with psoriasis. Another limit of our study could be the fact that as we do not have additional follow up data (i.e. 6 months after discharge from hospital), we cannot judge the long-term effects of improvement of psoriasis (PASI) on the patients' QOL.

\section{CONCLUSIONS}

Psoriasis is one of the most common chronic inflammatory skin diseases, the prevalence and treatment of which can negatively affect the QOL of patients. We assessed the QOL of 51 patients with moderate to severe psoriasis treated by Goeckerman therapy. It was found that QOL of our patients was relatively good. This finding could be explained by the fact that our patients have been suffering from psoriasis for many years and therefore have probably already adapted to the disease. QOL of our patients was not directly dependent on the extent and intensity of skin changes. Despite the significant improvement in the PASI score, we found minor, mostly insignificant, deterioration in QOL one month after hospital discharge. Studies on the association between psoriasis and/or its therapy and patients QOL are still needed.

\section{Acknowledgements}

This study was supported by the Faculty of Medicine in Hradec Králové, Charles University, Prague, Czech Republic (PROGRES Q 40/09), and by the Ministry of Education, Youth and Sports of the Czech Republic (Specific university research project SVV-260397/2017).

\section{Adherence to Ethical Standards}

The study was approved by the Ethics Committee of Medical Faculty of Charles University, University Hospital and Purkyně Military Medical Academy in Hradec Králové.

\section{Conflict of Interests}

None declared

\section{REFERENCES}

1. Puig L, Thom H, Mollon P, Tian H, Ramakrishna GS. Clear or almost clear skin improves the quality of life in patients with moderate-to-severe psoriasis: a systemic review and meta-analysis. J Eur Acad Dermatol Venerol. 2017;31(2):213-20.

2. Sojević Timotijević Z, Majcan P, Trajković G, Relić M, Novaković T, Mirković M, et al. The impact of changes in psoriasis area and severity index by body region on quality of life in patients with psoriasis. Acta Dermatovenerol Croat. 2017;25(3):215-22.

3. De Arruda LH, De Morales AP. The impact of psoriasis on quality of life. Br J Dermatol. 2001;144 Suppl 58:33-6.

4. Krueger G, Koo J, Lebwohl M, Menter A, Stern RS, Rolstad T. The impact of psoriasis on quality of life: results of a 1998 National Psoriasis Foundation patient-membership survey. Arch Dermatol. 2001;137(3):280-4.

5. Neimann AL, Shin DB, Wang X, Margolis DJ, Troxel AB, Gelfand JM. Prevalence of cardiovascular risk factors in patients with psoriasis. J Am Acad Dermatol. 2006;55(5):829-35.

6. Sarkar R, Chugh S, Bansal S. General measures and quality of life issues in psoriasis. Indian Dermatol Online J. 2016;7(6):481-8.

7. Vardy D, Besser A, Amir M, Gesthalter B, Biton A, Buskila D. Experiences of stigmatization play a role in mediating the impact of disease severity on quality of life in psoriasis patients. Br J Dermatol. 2002;147(4):736-42.

8. Schmitt JM, Ford DE. Role of depression on quality of life for patients with psoriasis. Dermatology. 2007;215(1):17-27.

9. Rapp SR, Feldman SR, Exum ML, Fleischer AB Jr, Reboussin DM. Psoriasis causes as much disability as other major medical diseases. J Am Acad Dermatol. 1999;41(3 Pt 1):401-7.

10. McKenna SP, Cook SA, Whalley D, Doward LC, Richards HL, Griffiths $\mathrm{CE}$, et al. Development of the PSORIQoL, a psoriasis-specific measure of quality of life designed for use in clinical practice and trials. $\mathrm{Br} \mathrm{J}$ Dermatol. 2003;149(2):323-31.

11. Lee E, Koo J. Modern modified 'ultra' Goeckerman therapy: a PASI assessment of a very effective therapy for psoriasis resistant to both prebiologic and biologic therapies. J Dermatolog Treat. 2005;16(2):102-7.

12. Chern E, Yau D, Ho JC, Wu WM, Wang CY, Chang HW, et al. Positive effect of modified Goeckerman regimen on quality of life and psychosocial distress in moderate and severe psoriasis. Acta Derm Venereol. 2011;91(4):447-51. 
13. Dennis M, Bhutani T, Koo J, Liao W. Goeckerman therapy for the treatment of eczema: a practical guide and review of efficacy. J Dermatolog Treat. 2013;24(1):2-6.

14. Finlay AY, Coles EC. The effect of severe psoriasis on the quality of life of 369 patients. Br J Dermatol. 1995;132(2):236-44.

15. Balaštík D, Semrádová V. Distribution of some variables in the sample of psoriatics and their modification by group psychotherapy. Ceskoslov Psychol. 2007;51(2):183-97. (In Czech.)

16. Abrouk M, Nakamura M, Zhu TH, Farahnik B, Koo J, Bhutani T. The impact of PASI 75 and PASI 90 on quality of life in moderate to severe psoriasis patients. J Dermatolog Treat. 2017;28(6):488-91.

17. He Z, Lu C, Ou A, Fang J, Wang D, Deng J, et al. Reliability and validity of the Chinese version of the Psoriasis Disability Index (PDI) in Chinese patients with psoriasis. Health Qual Life Outcomes. 2012;10:37. doi: 10.1186/1477-7525-10-37.

18. Mahmutovic J, Zukic M, Pasalic A, Brankovic S, Jaganjac A, Katana B. Correlation between quality of life and depression among persons suffering from psoriasis. Med Arch. 2017;71(5):341-6.

19. Lee YW, Park EJ, Kwon IH, Kim KH, Kim KJ. Impact of psoriasis on quality of life: relationship between clinical response to therapy and change in health-related quality of life. Ann Dermatol. 2010;22(4):389-96.
20. Semrádová V, Balaštík D. The quality of life measurement in patients with psoriasis. Ceskoslov Dermatol. 2003;78(6):228-31. (In Czech.)

21. Semrádová V, Vašků V, Balaštík D, Slonková V. Quality of life in patients with psoriasis vulgaris. I. The impact of therapy on the quality of life. Ceskoslov Dermatol. 2006;81(3):153-61. (In Czech.)

22. Fortune DG, Richards HL, Main CJ, Griffiths CE. Patients' strategies for coping with psoriasis. Clin Exp Dermatol. 2002;27(3):177-84.

23. Gelfand JM, Feldman SR, Stern RS, Thomas J, Rolstad T, Margolis DJ. Determinants of quality of life in patients with psoriasis: a study from the US population. J Am Acad Dermatol. 2004;51(5):704-8.

24. McKenna KE, Stern RS. The impact of psoriasis on the quality of life of patients from the 16-center PUVA follow-up cohort. J Am Acad Dermatol. 1997;36(3 Pt 1):388-94.

25. Naldi L, Mercuri SR. Epidemiology of comorbidities in psoriasis. Dermatol Ther. 2010;23(2):114-8.

Received November 15, 2018 Accepted in revised form June 8, 2020 